\title{
Avaliação de Contribuições Teóricas ao Método das Unidades de Esforço de Produção (UEPs)
}

\author{
Thiago Leal Summchen Valentim \\ Mestrado em Engenharia de Produção pela Universidade Federal do Rio Grande do \\ Sul - UFRGS \\ Av. Paulo Gama, 110. Farroupilha. Porto Alegre/RS. CEP: 90040-060 \\ E-mail: thiagov4@hotmail.com
}

\section{RESUMO}

A gestão estratégica de custos emerge como um elemento-chave para o bom desempenho das organizações, destacando-se a importância da discussão sobre sistemas de custeio e sua adequação ao ambiente aplicado. Neste contexto, o presente trabalho objetiva avaliar duas contribuições conceituais ao método das Unidades de Esforço de Produção (UEPs), partindo da análise de sua aplicação prática. Ele busca ampliar a discussão a respeito do método com a proposição de dois pontos: a divisão de UEPs em fixas e variáveis e o cálculo de UEPs parciais. Para tanto, apoia-se em um estudo de caso realizado em uma empresa que atua na produção de instrumentos de medição. Como resultado, é possível concluir que a primeira modificação proposta torna o método mais robusto na questão da avaliação econômica das perdas de processo, além de aprofundar a sua discussão sobre capacidade produtiva. Por outro lado, a segunda contribuição visa à minimização de distorções por grau de média no custeio das UEPs, de forma a melhor distribuir o custo das ineficiências do processo para os diversos produtos. Conclui-se que ambas as contribuições são pertinentes ao método e ampliam sua abrangência, especialmente em pontos como a análise econômica de perdas e ineficiências.

Palavras-chave: Método das UEPs. Análise econômica de perdas. Custos de produção.

\section{Assessment of Thoretical Contributions to the Unity of Production Effort Method (UPE)}

\section{ABSTRACT}

The strategic cost management emerges as a key element to an optimal performance of organizations, highlighting the importance of the discussion on costing methods and its adaptation to each case of application. In this context, this paper aims to assess two theoretical contributions to the costing method Unity of Production Effort (UPE), based on the analysis of its practical application. It seeks to broaden the discussion regarding the method with a two-point proposition: the division of the UPE into fixed and variable portions and the calculation of partial UPEs. To this extent, it builds on a case study conducted in a company that produces and sells measurement instruments. As a result, it is possible to conclude that the first theoretical proposition makes the method more robust in the economic 
assessment of production losses, as well as deepens its discussion regarding production capacity. On the other hand, the second contribution aims to minimize the distortions in the costing proceedings of this method. It is concluded that both propositions are pertinent to the subject and broaden the discussions that it spawns, in special regarding the issue of economic assessment of production losses and inefficiencies.

Key-words: UPE Method. Economic assessment of production losses. Production costs.

\section{INTRODUÇÃO}

A gestão estratégica de custos tem emergido como um elemento-chave para o bom desempenho das organizações, buscando o desenvolvimento de métodos que forneçam informações confiáveis tanto para o controle de gastos quanto para o apoio à tomada de decisões (Fagundes, 2009; Schwanke \& Kliemann Neto, 2010). Neste contexto, destaca-se a importância da discussão sobre sistemas de custeio e sua adequação ao ambiente aplicado, em especial considerando as características de uma empresa moderna, em constante mudança.

Métodos de custeio tradicionais vêm se tornando obsoletos frente a este cenário e foram aprimorados com o tempo, buscando-se a otimização do processo de tomada de decisão. O método das Unidades de Esforço de Produção (UEPs) surge como uma alternativa que busca mitigar distorções na identificação e distribuição de custos operacionais.

Segundo Cambruzzi, Balen e Morozini (2009), o método das UEPs busca simplificar o processo de apropriação de custos de transformação a partir da unificação da medida de produção, introduzindo uma unidade comum a todos os produtos, a qual fundamenta-se no conceito de esforço produtivo. Este conceito representa o esforço empregado no processo de transformação de matéria-prima em produtos finais. Assim, o método procura criar padrões econômicos de referência para produtos e operações, permitindo maior acurácia no cálculo de custos de transformação e na análise econômica de eficiência dos processos.

O presente trabalho tem como tema o método das UEPs e seu desenvolvimento teórico e prático. Seu objetivo principal é a avaliação de duas contribuições conceituais ao método: a divisão de UEPs em fixas e variáveis e o 
cálculo de UEPs parciais. Essas contribuições visam ampliar o escopo deste método no que diz respeito à análise econômica de perdas, capacidade produtiva e minimização de distorções no custeio de produtos. Para tanto, fundamenta-se no trabalho de Bastos (2015), o qual é utilizado para validar as contribuições propostas e apresenta a aplicação do método em uma empresa de manufatura. $O$ trabalho tem como objetivo secundário, ainda, a análise crítica desta aplicação como base para a realização das proposições.

O artigo está dividido em cinco seções. A seção 1 apresenta a introdução, delineando o contexto do trabalho e apresentando seu tema e objetivo. A seção 2 traz uma revisão da literatura referente a sistemas de custeio e, em especial, sobre o método das UEPs. A seção 3 enfoca os procedimentos metodológicos adotados no trabalho. Na seção 4, são apresentados e discutidos os resultados obtidos e, por fim, na seção 5 , são tecidas as considerações finais.

\section{REFERENCIAL TEÓRICO}

Este referencial inicia apresentando conceitos acerca de sistemas de custeio e, a seguir, aprofunda a discussão a respeito do método das UEPs.

\subsection{Sistemas de custos}

Bornia (2010) define um sistema de custos a partir de duas óticas. Por um lado, ele direciona o tratamento das informações, determinando quais são relevantes e que devem ser geradas pelo sistema. Por outro lado, ele trata da problemática de alocação de custos indiretos aos produtos, definindo de que forma os dados são processados. A primeira visão diz respeito aos princípios de custeio e a segunda, aos métodos de custeio. Segundo Campagnolo, Souza e Kliemann Neto (2009), um sistema de custos é definido pela associação de princípios e métodos.

Os métodos de custeio permitem a operacionalização das informações levantadas pelos princípios. Fadanelli (2007) e Bornia (2010) identificam como principais métodos de custeio: Custo Padrão, Centros de Custos, Custeio Baseado em Atividades (ABC ou Activity-Based Costing), Time-Driven Activity-Based Costing (TDABC) e Unidades de Esforço de Produção (UEPs). Campagnolo et al. (2009) 
distinguem uma divisão entre estes métodos, classificando os dois primeiros como Métodos Tradicionais e os três últimos como Métodos Modernos. O Quadro 1 apresenta um breve comparativo entre esses métodos com relação a certos fatores considerados críticos na sua aplicação.

\begin{tabular}{|c|c|c|c|c|c|}
\hline & Custo Padrão & Centro de Custos & ABC & TDABC & UEP \\
\hline Matéria-Prima & Considera & Não considera & Não considera & Não considera & Não considera \\
\hline $\begin{array}{l}\text { Eficiência na apropriação de } \\
\text { custos de transformação }\end{array}$ & Não considera. & $\begin{array}{c}\text { Considerado ineficaz } \\
\text { devido ao alto grau de } \\
\text { rateio. }\end{array}$ & $\begin{array}{l}\text { Indicado para } \\
\text { organizações com } \\
\text { custos de } \\
\text { transformação } \\
\text { representativos, } \\
\text { particularmente nas } \\
\text { áreas de apoio. }\end{array}$ & $\begin{array}{l}\text { Indicado para } \\
\text { organizações com } \\
\text { custos de } \\
\text { transformação } \\
\text { representativos, } \\
\text { particularmente nas } \\
\text { áreas de apoio. }\end{array}$ & $\begin{array}{c}\text { Indicado para } \\
\text { organizações com } \\
\text { custos de } \\
\text { transformação } \\
\text { representativos, } \\
\text { particularmente na } \\
\text { área industrial. }\end{array}$ \\
\hline Análise de perdas & $\begin{array}{l}\text { Proporciona análise } \\
\text { de perdas pela } \\
\text { comparação entre } \\
\text { padrões de consumo } \\
\text { e quantidades reais. }\end{array}$ & $\begin{array}{l}\text { Pela estrutura por } \\
\text { departamentos, } \\
\text { dificulta correta } \\
\text { identificação de } \\
\text { perdas. }\end{array}$ & $\begin{array}{c}\text { Superficial e feita de } \\
\text { forma consolidada, } \\
\text { sem detalhamento por } \\
\text { produto ou operação. }\end{array}$ & $\begin{array}{c}\text { Proporciona uma } \\
\text { análise satisfatória, } \\
\text { mas nãoo detalha por } \\
\text { operação ou produto. }\end{array}$ & $\begin{array}{l}\text { Proporciona um boa } \\
\text { avaliação na área } \\
\text { industrial, detalhada } \\
\text { por operação e } \\
\text { produto. }\end{array}$ \\
\hline Implementação & Simples e fácil. & Simples e fácil. & $\begin{array}{l}\text { Considerada } \\
\text { complexa devido à } \\
\text { quantidade de } \\
\text { informações } \\
\text { necessárias. }\end{array}$ & \begin{tabular}{|c|} 
Dificuldade média. Em \\
comparação ao $A B C$, \\
exige menor \\
quantidade de \\
informações.
\end{tabular} & Dificuldade média. \\
\hline Resistência à implementação & Baixa & Baixa & Alta & Média & Média \\
\hline Custo de transação & Baixo & Baixo & Alto & Médio & Médio \\
\hline Facilidade de atualização & Simples e fácil. & $\begin{array}{l}\text { Simples e fácil, mas } \\
\text { não representativa. }\end{array}$ & $\begin{array}{l}\text { Complexa, devido ao } \\
\text { alto grau de } \\
\text { informações } \\
\text { necessário. }\end{array}$ & $\begin{array}{c}\text { Média, pois exige } \\
\text { revisão de critérios de } \\
\text { rateio. }\end{array}$ & $\begin{array}{l}\text { Grande, pois apóia-se } \\
\text { em padrão de } \\
\text { referência. }\end{array}$ \\
\hline Banco de dados necessário & Pequeno & Pequeno & Grande & Médio & Médio \\
\hline
\end{tabular}

Quadro 1. Comparativo entre os métodos de custeio.

Nota. Fonte: Adaptado de Campagnolo et al. (2009)

Por ser tema central deste artigo, a seguir apresenta-se um breve referencial teórico sobre o método das Unidades de Esforço de Produção (UEPs).

\subsection{0 método das UEPs}

O método das UEPs surgiu no intuito de mensurar e alocar com maior acurácia os custos de transformação das empresas industriais aos seus produtos e serviços. Ele tem como objetivo principal a unificação da produção para simplificar o processo de controle e gestão de custos (Cambruzzi et al., 2009; Campagnolo et al., 2009). Para tanto, busca a definição de uma unidade abstrata, comum e homogênea, capaz de medir produções diversificadas (Morozini, Gass, Caerpenedo, \& Zuffo, 2006). Esta unidade é fundamentada no conceito de esforço de produção e 
surge em contraste com as unidades de medida normalmente utilizadas por empresas multiprodutoras, como quilogramas e horas, que não representam o verdadeiro valor da produção, por somarem produtos distintos (Allora \& Gantzel, 1996).

Cambruzzi et al. (2009) afirmam que a noção de esforço produtivo está associada à soma dos esforços necessários à fabricação dos produtos e os dividem em: esforço material (referente a materiais de consumo e ferramentas); esforços salariais (referentes aos gastos com mão de obra); esforço de capital (representado pela depreciação de máquinas e equipamentos); esforço de energia elétrica e utilidades, além de outros esforços indiretos necessários à produção, como a manutenção de equipamentos. O método parte do pressuposto de que o produto de uma empresa é o esforço que ela gera para a fabricação de seus produtos, a partir do consumo dos insumos e da matéria-prima. Valentim, Kliemann Neto, Correa, Denicol e Cassel (2014) acrescentam que ele trabalha apenas com custos de transformação, não levando em conta os custos de matéria-prima, considerada um mero objeto de trabalho.

Para o método, os focos concentradores dos esforços são as atividades produtivas envolvidas diretamente na fabricação dos produtos. Assim, ele introduz o conceito de Postos Operativos (POs), os quais são definidos como conjuntos de uma ou mais operações produtivas homogêneas, que possuem capacidade de gerar esforços (Bornia, 2010). Os produtos consomem esses esforços e seus custos de transformação associados; assim, a produção de uma empresa pode ser medida pela soma dos esforços gerados na fabricação dos produtos. O custo final de transformação é dado pela soma dos custos dos esforços absorvidos pelos produtos durante o processo (Campagnolo et al., 2009).

Wernke e Lembeck (2008) e Wernke, Junges e Cláudio (2012) identificam como principais benefícios do método a compreensão que ele proporciona da estrutura de custos de transformação da empresa, a obtenção de informações de custos mais confiáveis, bem como a obtenção de indicadores de desempenho não financeiros para avaliar o desempenho da produção. Os autores destacam, ainda, que o método proporciona uma gama de informações gerenciais importantes, entre as quais: 
a) Apuração dos custos de transformação, reduzindo distorções;

b) Apuração da capacidade produtiva da fábrica e sua utilização em UEPs;

c) Identificação dos potenciais produtivos (UEPs/hora) dos postos operativos;

d) Possibilidade de análise comparativa entre diferentes etapas do processo;

e) Utilização da UEP na construção de medidas de desempenho da produção.

Bornia (2010), por outro lado, destaca seu enfoque restrito ao processo produtivo, desconsiderando gastos com matéria-prima, bem como a necessidade de aprofundamento na sua capacidade de identificação e tratamento de perdas produtivas, como as principais limitações do método.

\subsection{Aplicação do método das UEPs}

A aplicação do método das UEPs envolve uma série de etapas a serem seguidas. Valentim et al. (2014) propõem uma sistemática de aplicação em quatro fases, a qual é apresentada na Figura 1 e discutida na sequência:

1. Compreensão do cenário: busca compreender o contexto de aplicação, a estrutura organizacional, produtiva e de custos da empresa.

2. Implantação do método: corresponde à definição de seus parâmetros. Parte da divisão da empresa em POs e da determinação de seus custos horários de operação (foto-índices), usualmente estratificados conforme mencionado anteriormente. Em paralelo, faz-se a definição do produto-base, o qual deve ser representativo do mix de produtos e tem o intuito de absorver variações a longo prazo nos itens de custo considerados, bem como o cálculo do custo deste produto, denominado foto-custo base. Segundo Fadanelli (2007), o custo do produto-base é a expressão do custo do esforço necessário para a realização de uma UEP. De posse dessas informações, é possível calcular os potenciais produtivos dos POs (em UEPs/hora), definidos pela divisão dos foto-índices de cada posto pelo foto-custo base, que representam a sua capacidade de produção de UEPs. Por fim, partindo dos roteiros dos produtos, calculam-se seus equivalentes em UEPs, com a multiplicação dos tempos de fabricação pelo potencial produtivo de cada PO. 
3. Operacionalização do método: consiste em um conjunto de cálculos rotineiros que representam os resultados do método. Entre eles estão: (i) determinação do total produzido em UEPs, pela multiplicação das quantidades físicas produzidas pelos equivalentes em UEPs; (ii) a monetarização da UEP, dividindo-se o total dos custos de transformação do período pela produção total em UEPs; (iii) o cálculo dos custos de transformação dos produtos, multiplicando-se o valor monetário da UEP pelos respectivos equivalentes; (iv) o cálculo de medidas de desempenho do processo.

4. Consolidação dos resultados: etapa de feedback da sistemática.

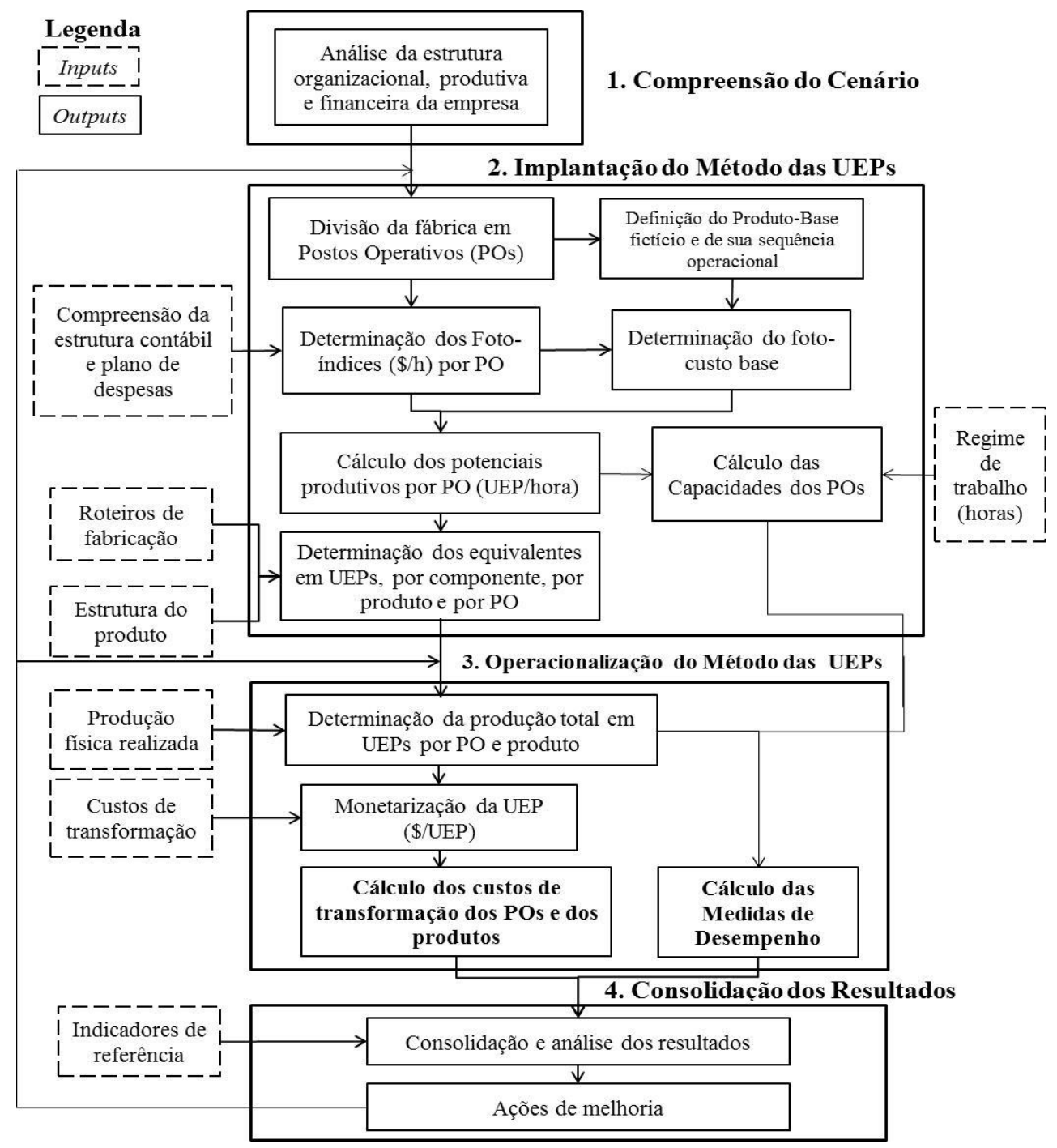

Figura 1. Sistemática de aplicação do método das UEPs

Nota. Fonte: Valentim et al. (2014) 


\section{PROCEDIMENTOS METODOLÓGICOS}

No que diz respeito ao método de pesquisa, este artigo apresenta um estudo de caso, o qual é definido por Gil (2002) como um estudo profundo e exaustivo de um ou mais objetos, possibilitando a obtenção de um amplo conhecimento sobre o assunto. Este estudo é utilizado de base para a proposição de contribuições teóricas à aplicação de um método já estabelecido. Quanto à sua natureza, pode ser classificado como uma pesquisa explicativa. A abordagem da pesquisa pode ser classificada como qualitativa, por envolver um estudo de caso, a avaliação crítica de uma situação real e a proposição de melhorias.

O método de trabalho proposto consiste de três etapas. Na primeira etapa, propõe-se a compreensão do contexto atual da empresa estudada, a partir de uma análise crítica de seu sistema de custeio atual e seus resultados obtidos. A seguir, procede-se a uma análise da aplicação do método das UEPs na empresa em questão. Busca-se avaliar a adequação do método à realidade da empresa, apresentar alguns resultados obtidos e realizar uma análise comparativa destes resultados com as informações geradas pelo atual sistema de custeio, destacando e justificando as principais divergências identificadas.

Por fim, a última etapa envolve uma proposta de melhoria na estrutura de aplicação do método das UEPs, buscando incorporar novos elementos à sua implantação e operacionalização. Esta proposta foca duas contribuições:

(i) Divisão entre UEPs Fixas e Variáveis: tem o objetivo de refinar a análise de capacidade produtiva permitida pelo método, bem como desdobrar a análise econômica de perdas de custo do processo, levando em conta a diferenciação entre a utilização de estrutura fixa e variável;

(ii) Cálculo de UEPs Parciais: considera o cálculo e a valorização de UEPs por grupos de postos operativos, em contraste com o cálculo de uma única quantidade de UEPs global, de modo a distribuir os custos de transformação de uma forma mais precisa para o mix de produção da empresa, considerando que as famílias de produtos se utilizam da estrutura de POs de forma distinta. 


\section{RESULTADOS}

Esta seção do artigo busca apresentar as discussões propostas, seguindo as etapas apresentadas nos procedimentos metodológicos.

\subsection{Compreensão da situação atual}

O presente trabalho foi realizado em uma empresa de manufatura que fabrica e comercializa equipamentos e instrumentos de medição. Seu portfólio de produtos abrange mais de três mil itens, contando tanto com fabricação própria quanto itens importados que são apenas embalados e revendidos. Possui ênfase nas áreas da saúde e na área técnica. Seu processo produtivo conta com aproximadamente 100 colaboradores e atende demandas de perfis distintos, dado que a empresa possui tanto produtos por encomenda quanto por fabricação em lotes. Este processo possui característica geral de fabricação artesanal, com alguns setores compostos quase exclusivamente por trabalho manual, enquanto outros possuem um grau maior de automatização. Adicionalmente, caracteriza-se pela heterogeneidade de custos operacionais e tempos de processamento dos produtos.

O atual sistema de custeio da empresa está fundamentado na associação do método dos Centros de Custos com o princípio da Absorção Total. A empresa possui dez centros de custos indiretos e onze centros produtivos, e os critérios de rateio utilizados pelo sistema são arbitrários, definidos sem o apoio de parâmetros técnicos, mas, sim, a partir das opiniões de pessoas envolvidas no processo. Em contraste ao apresentado usualmente na literatura, os custos indiretos não são totalmente distribuídos à produção, sendo definidos percentuais dos custos de cada centro indireto que são rateados aos centros produtivos.

Após o rateio, o custo total dos centros produtivos é dividido pela soma das horas padrão dos produtos, obtendo-se as taxas-hora de cada centro direto. Assim, com a multiplicação dos tempos de roteiro de cada produto pelos custos-hora, obtêm-se os custos unitários de fabricação. No que diz respeito aos custos de matéria-prima, a empresa não utiliza nenhuma metodologia para seu controle gerencial, tendo em vista que sua representatividade média nos custos totais de produção é considerada baixa (em torno de 10\% nos itens de fabricação interna). 
A Tabela 1 apresenta os índices horários de custo dos centros produtivos para o mês estudado.

Tabela 1

Índices de custos obtidos pelo método de custeio atual

\begin{tabular}{|c|c|c|c|c|c|c|}
\hline Setor & CC & Horas & & usto & & ora \\
\hline CC PRODUTIVO 1 & 122001 & 1.233 & $\mathrm{R} \$$ & $46.268,93$ & $\mathbf{R} \$$ & 37,53 \\
\hline CC PRODUTIVO 2 & 122002 & 163 & $\mathrm{R} \$$ & $18.667,16$ & $\mathbf{R} \$$ & 114,69 \\
\hline CC PRODUTIVO 3 & 122003 & 662 & $\mathrm{R} \$$ & $29.066,19$ & $\mathbf{R} \$$ & 43,91 \\
\hline CC PRODUTIVO 4 & 122004 & 112 & $\mathrm{R} \$$ & $15.413,26$ & $\mathbf{R} \$$ & 137,76 \\
\hline CC PRODUTIVO 5 & 122005 & 554 & $\mathrm{R} \$$ & $21.295,48$ & $\mathbf{R} \$$ & 38,46 \\
\hline CC PRODUTIVO 6 & 122006 & 193 & $\mathrm{R} \$$ & $21.318,56$ & $\mathbf{R} \$$ & 110,35 \\
\hline CC PRODUTIVO 7 & 122009 & 1.893 & $\mathrm{R} \$$ & $67.077,00$ & $\mathbf{R} \$$ & 35,43 \\
\hline CC PRODUTIVO 8 & 122012 & - & $\mathrm{R} \$$ & $6.365,73$ & $\mathbf{R} \$$ & - \\
\hline CC PRODUTIVO 9 & 122013 & 84 & $\mathrm{R} \$$ & $10.865,55$ & $\mathbf{R} \$$ & 129,30 \\
\hline CC PRODUTIVO 10 & 122014 & 482 & $\mathrm{R} \$$ & $32.132,89$ & $\mathbf{R} \$$ & 66,67 \\
\hline CC PRODUTIVO 11 & 122020 & 57 & $\mathrm{R} \$$ & $20.197,24$ & $\mathbf{R} \$$ & 356,42 \\
\hline
\end{tabular}

\subsection{Análise da aplicação do método das UEPs}

Após a etapa de compreensão do cenário, o trabalho se propõe analisar a aplicação do método das UEPs no setor produtivo da empresa, bem como comparar seus resultados com os obtidos pela aplicação do método de custeio atual. Nesta seção, serão discutidos os principais resultados e contribuições.

A empresa estudada apresenta um ambiente considerado adequado à aplicação do método, tendo em vista que aproximadamente metade de sua estrutura é voltada à área de manufatura. Seu processo apresenta uma característica de heterogeneidade em relação aos recursos empregados e sua utilização pelos itens produzidos. Isto ficou claro desde o início da implantação, em que os onze centros de custos produtivos foram divididos em 35 postos operativos.

Foi definido um produto-base real, uma das famílias de produto da empresa chamada aqui de Linha $A$, para o qual foi calculado um foto-custo base de $R \$ 3,02$. A partir deste cálculo, foram definidos os potenciais produtivos dos POs, apresentados na Tabela 2. De fato, percebe-se uma ampla variação na capacidade de geração de esforços dentro do processo, com potenciais variando desde 0,75 até 31,67 UEPs/hora. Adicionalmente, é possível notar que o método das UEPs permite lidar com a heterogeneidade do processo onde ela existe. Por exemplo, os centros de custos 1, 3 e 7, ao serem decompostos em seus respectivos POs, revelaram-se 
bem heterogêneos em termos de potencial produtivo, ou seja, são compostos por operações com diferentes níveis de agregação de valor, característica que permanecia oculta na estrutura de centros de custos.

Tabela 2

Potenciais produtivos dos Pos (UEPs/hora)

\begin{tabular}{|c|c|c|c|c|c|c|c|c|}
\hline $\mathrm{CC}$ & $\mathrm{PO}$ & $\begin{array}{c}\text { UEPs/Hora } \\
\text { Total }\end{array}$ & $\mathrm{CC}$ & $\mathrm{PO}$ & $\begin{array}{c}\text { UEPs/Hora } \\
\text { Total }\end{array}$ & $\mathrm{CC}$ & $\mathrm{PO}$ & $\begin{array}{c}\text { UEPs/Hora } \\
\text { Total }\end{array}$ \\
\hline $\mathrm{CC} 1$ & PO-034 & 6,74 & $\mathrm{CC} 4$ & $\mathrm{PO}-004$ & 7,75 & $\mathrm{CC} 7$ & $\mathrm{PO}-030$ & 11,43 \\
\hline $\mathrm{CC} 1$ & PO-036 & 6,72 & $\mathrm{CC} 4$ & $\mathrm{PO}-010$ & 6,75 & $\mathrm{CC} 7$ & PO-032 & 15,29 \\
\hline $\mathrm{CC} 1$ & $\mathrm{PO}-044$ & 6,72 & $\mathrm{CC} 4$ & $\mathrm{PO}-012$ & 6,48 & $\mathrm{CC} 7$ & PO-052 & 6,28 \\
\hline $\mathrm{CC} 1$ & $\mathrm{PO}-046$ & 0,75 & $\mathrm{CC} 5$ & $\mathrm{PO}-050$ & 7,90 & $\mathrm{CC} 7$ & $\mathrm{PO}-060$ & 13,58 \\
\hline $\mathrm{CC} 1$ & PO-084 & 8,28 & $\mathrm{CC} 5$ & PO-076 & 7,34 & $\mathrm{CC} 7$ & PO-062 & 7,61 \\
\hline $\mathrm{CC} 1$ & PO-086 & 6,92 & $\mathrm{CC} 6$ & $\mathrm{PO}-002$ & 7,66 & $\mathrm{CC} 7$ & $\mathrm{PO}-070$ & 14,22 \\
\hline $\mathrm{CC} 2$ & PO-008 & 13,65 & CC6 & PO-054 & 7,63 & $\mathrm{CC} 7$ & $\mathrm{PO}-072$ & 31,67 \\
\hline $\mathrm{CC} 2$ & PO-038 & 13,75 & CC6 & $\mathrm{PO}-056$ & 8,74 & CC9 & $\mathrm{PO}-016$ & 8,08 \\
\hline $\mathrm{CC} 2$ & $\mathrm{PO}-064$ & 13,62 & CC6 & $\mathrm{PO}-058$ & 9,20 & CC9 & $\mathrm{PO}-048$ & 8,11 \\
\hline $\mathrm{CC} 3$ & PO-006 & 7,22 & $\mathrm{CC} 8$ & $\mathrm{PO}-040$ & 10,13 & CC9 & PO-090 & 8,22 \\
\hline $\mathrm{CC} 3$ & PO-014 & 8,33 & $\mathrm{CC} 8$ & $\mathrm{PO}-078$ & 10,08 & CC10 & PO-074 & 7,81 \\
\hline $\mathrm{CC} 3$ & $\mathrm{PO}-080$ & 5,62 & & & & CC11 & $\mathrm{PO}-082$ & 8,91 \\
\hline
\end{tabular}

Após este passo, seguiu-se um trabalho de agrupamento do portfólio de produtos da empresa em famílias, para simplificar o processo de controle e custeio, e foram definidos seus equivalentes em UEP, a partir de seus roteiros de fabricação. Houve a necessidade de um trabalho extenso de roteirização dos principais itens produzidos, os quais não possuíam tempos-padrão de operação.

A produção total do mês foi obtida pela multiplicação dos equivalentes em UEPs pelas quantidades físicas de todos os itens produzidos no mês. Os custos de transformação do período foram obtidos junto à área de Contabilidade e, com a divisão deste total pela produção em UEPs, foi possível obter o custo de uma UEP, confirme a Tabela 3. Destaca-se, aqui, que o método está sendo aplicado em conjunto com o princípio de Absorção Total.

Tabela 3

Monetarização da UEP no período

\begin{tabular}{|c|c|c|}
\hline Total em UEPs & $\begin{array}{c}\text { Custos de } \\
\text { Transformação }(\$)\end{array}$ & Custo por UEP \\
\hline $46.337,60$ & $\mathrm{R} \$ 288.668,00$ & $\mathbf{R} \$ \mathbf{6 , 2 3}$ \\
\hline
\end{tabular}


De posse do custo de cada UEP e dos equivalentes das famílias de produtos, foi possível calcular seus custos unitários de transformação, o que se configura como o principal resultado da aplicação do método.

Neste trabalho, propõe-se a consolidação dos resultados do método, procedendo-se à sua análise comparativa frente às informações já obtidas com o método atual. Dessa forma, foram selecionadas duas famílias de produtos, chamadas $A$ e $B$, e calcularam-se seus custos de transformação por ambos os métodos. As Tabelas $4 \mathrm{e}$ 5 mostram esta comparação para ambas as famílias. Para que a base de comparação fosse a mesma, nos dois métodos se utilizou o princípio da Absorção Total.

Tabela 4

Comparativo entre métodos de custeio - família $A$

\begin{tabular}{|c|c|c|c|c|c|c|c|c|c|c|c|c|c|c|}
\hline & CCs & CC 1 & $\mathrm{CC} 1$ & CC 1 & CC 1 & CC 2 & $\mathrm{CC} 4$ & $\mathrm{CC} 5$ & $\mathrm{CC} 6$ & CC 7 & CC 7 & CC 7 & CC 10 & TOT \\
\hline & POs & $\mathrm{PO}-044$ & PO-046 & PO-084 & PO-086 & PO-038 & PO-004 & PO-076 & PO-058 & PO-030 & PO-052 & PO-072 & PO-074 & \\
\hline \multirow{4}{*}{ UEPs } & Horas & 0,0068 & 0,0080 & 0,0062 & 0,0107 & 0,0149 & 0,0183 & 0,0358 & 0,0153 & 0,0007 & 0,0003 & 0,0005 & 0,0062 & 0,1236 \\
\hline & Potenciais & 6,74 & 0,75 & 8,3 & 6,94 & 13,92 & 7,51 & 7,36 & 9,22 & 11,47 & 6,3 & 31,76 & 7,83 & \\
\hline & Equivalente & 0,0458 & 0,0060 & 0,0515 & 0,0743 & 0,2074 & 0,1374 & 0,2635 & 0,1411 & 0,0080 & 0,0019 & 0,0159 & 0,0485 & \\
\hline & CUSTO & $\mathrm{R} \$ 0,29$ & $R \$ 0,04$ & $R \$ 0,32$ & $\mathrm{R} \$ \mathbf{0 , 4 6}$ & $\mathrm{R} \$ 1,29$ & $\mathrm{R} \$ 0,86$ & $R \$ 1,64$ & $\mathrm{R} \$ \mathbf{0 , 8 8}$ & $\mathrm{R} \$ 0,05$ & $\mathrm{R} \$ 0,01$ & $\mathrm{R} \$ 0,10$ & $R \$ 0,30$ & $\mathrm{R} \$ 6,24$ \\
\hline \multirow{3}{*}{ CCs } & Horas & \multicolumn{4}{|c|}{0,032} & 0,015 & 0,018 & 0,036 & 0,015 & & 0,001 & & 0,006 & 0,124 \\
\hline & $\mathrm{R} \$$ /hora & \multicolumn{4}{|c|}{$\mathrm{R} \$ 37,5$} & $\mathrm{R} \$ 114,7$ & $\mathrm{R} \$ 137,8$ & $\mathrm{R} \$ 38,5$ & $\mathrm{R} \$ 110,4$ & & $\mathrm{R} \$ 35,4$ & & $\mathrm{R} \$ 66,7$ & \\
\hline & CUSTO & \multicolumn{4}{|c|}{$R \$ 1,20$} & $R \$ 1,72$ & $\mathrm{R} \$ \mathbf{2 , 4 8}$ & $R \$ 1,39$ & $R \$ 1,66$ & & $R \$ 0,04$ & & $R \$ 0,40$ & $R \$ 8,88$ \\
\hline
\end{tabular}

Tabela 5

Comparativo entre métodos de custeio - família B

\begin{tabular}{|c|c|c|c|c|c|}
\hline & CCs & $\mathrm{CC} 7$ & CC7 & $\mathrm{CC} 7$ & TOTAL \\
\hline & Pos & $\mathrm{PO}-032$ & PO-052 & PO-070 & \\
\hline \multirow{4}{*}{ UEPs } & Horas & 0,001 & 0,0003 & 0,0012 & 0,0025 \\
\hline & Potenciais & 15,34 & 6,3 & 14,27 & \\
\hline & Equivalente & 0,0153 & 0,0019 & 0,0171 & \\
\hline & CUSTO & $R \$ 0,10$ & $R \$ 0,01$ & $R \$ 0,11$ & $R \$ 0,21$ \\
\hline \multirow{3}{*}{ CCs } & Horas & & 0,002 & & $\mathrm{R} \$ 0,124$ \\
\hline & $\mathrm{R} \$ /$ Horas & & $\mathrm{R} \$ 35,4$ & & \\
\hline & CUSTO & & $R \$ 0,07$ & & $R \$ \mathbf{0 , 0 7}$ \\
\hline
\end{tabular}

Percebe-se uma diferença importante entre os custos obtidos. No caso dos produtos da família $A$, o método atual parece superestimar seus custos, com uma diferença relativa de $42 \%$. A análise pelo método das UEPs permite constatar que esses produtos gastam mais tempo de fabricação em POs de menor potencial 
produtivo, ou seja, que agregam menos valor. Assim, consomem esforços de recursos que oneram menos os produtos.

É possível notar, ainda, a distorção causada pelo grau de média inerente ao método dos Centros de Custos e que a UEP busca minimizar. Os produtos da família $A$ despendem 0,001 horas em três POs que, pelo método atual, são custeados por um único índice médio, enquanto, na realidade, estes POs possuem custos operacionais e potenciais produtivos distintos, como fica evidente na Tabela 4. Pelo método atual, o conjunto dessas três operações custa $R \$ 0,04$ por unidade, enquanto que o método das UEPs calcula um custo unitário de $R \$ 0,16$.

Por outro lado, o oposto ocorre com os produtos da Linha $B$, que têm seus custos subestimados pelo método atual, o qual distorce o fato de que o centro de custo utilizado é formado por operações de custos distintos, e os produtos desta linha passam a maior parte do tempo de fabricação nos POs de maior potencial. Assim, o custo unitário calculado pelo método das UEPs é maior do que o calculado pelo método atual por um fator de mais de duas vezes.

Esta análise, conquanto limitada a estes grupos de itens, destaca as diferenças nos resultados obtidos entre os dois métodos, indicando que a mesma situação pode estar ocorrendo nos demais itens do portfólio. Essas diferenças tornam-se mais importantes devido ao volume alto de itens que são fabricados mensalmente. Percebe-se que o método das UEPs, ao definir padrões econômicos de operação e relativizar a produção em termos de uma unidade padrão, é capaz de distinguir operações heterogêneas e, mediante a monetarização desta unidade, distribuir os custos de transformação de forma mais precisa. O método considera uma lógica não apenas de tempos de produção, mas também de valor agregado.

\subsection{Proposta de contribuições teóricas na aplicação do método}

Partindo da aplicação apresentada, este trabalho busca avaliar duas contribuições teóricas ao método, as quais são validadas utilizando-se os dados do mesmo estudo de caso. Estas contribuições surgem a partir de lacunas identificadas na sua aplicação. Primeiramente, discute-se a criação do conceito de UEPs fixas e variáveis. Esta abordagem busca desenvolver o potencial de análise econômica de perdas do método, a qual é apontada pela literatura como um de seus principais 
pontos de melhoria. Em um segundo momento, este trabalho apresenta o conceito de UEPs parciais, e seu impacto no custeio de produtos.

\subsubsection{UEPs Fixas e Variáveis}

A primeira proposta de melhoria deste trabalho busca contribuir com a problemática de valorização das perdas do processo produtivo por meio das UEPS, assim como expandir a discussão sobre capacidade produtiva proporcionada pelo método. Considerando-se que uma empresa possui parcelas de custos fixos e variáveis, ao realizar uma produção abaixo de sua capacidade máxima, a empresa, de um ponto de vista econômico, não perde todo o gap de capacidade não utilizada, já que uma parte desta capacidade está vinculada aos custos variáveis. Apenas a estrutura fixa do processo produtivo é comprometida.

Extrapolando este princípio para a aplicação do método, a divisão dos fotoíndices e, por consequência, dos potenciais produtivos em parcelas fixas e variáveis permite avaliar não somente a capacidade total do processo, mas também medir o quanto de esforço a empresa gera para uma produção boa e o quanto de esforços são perdidos em ineficiências e ociosidade. A parcela fixa da perda por ociosidade, a qual contém um esforço que poderia ter sido empregado na produção efetiva pode, então, ser incorporada à produção real do período, gerando um valor de nível de capacidade potencial.

Esta lógica de cálculo tem impacto tanto na implantação quanto na operacionalização do método. Na etapa de implantação, considerou-se a divisão dos itens de custo em parcelas fixas e variáveis, conforme apresentado na Tabela 6.

Tabela 6

Divisão dos itens de custos em fixos e variáveis.

\begin{tabular}{cccccccc}
\hline & MOD & MOI & Depreciação & Manut. MO & Manut. & Mat. Consumo & Energia \\
\hline Fixo & $80 \%$ & $80 \%$ & $50 \%$ & $80 \%$ & $30 \%$ & $0 \%$ & $20 \%$ \\
Variável & $20 \%$ & $20 \%$ & $50 \%$ & $20 \%$ & $70 \%$ & $100 \%$ & $80 \%$ \\
\hline
\end{tabular}

Estes percentuais foram definidos segundo critério de análise de histórico dos custos dos dois anos anteriores e identificação da parcela do custo total de cada item de custo que poderia ser classificada como custo variável. Por exemplo, itens 
como mão de obra são majoritariamente fixos, considerando salários e benefícios, porém existem remunerações variáveis que foram levadas em consideração na estimativa dos percentuais.

Esses percentuais foram aplicados aos custos-hora apresentados no Anexo A, gerando foto-índices fixos e variáveis. Por questão de espaço, a tabela com estes novos índices é omitida aqui. Percebe-se que os itens predominantemente fixos são aqueles de maior peso na estrutura de custos da empresa, ou seja, mão de obra direta e indireta. Logo, o custo da estrutura produtiva é mais fixo do que variável, o que gera desdobramentos nos esforços produtivos em potencial que a empresa deixa de utilizar.

O produto-base permanece inalterado, bem como seu foto-custo, de forma que esta divisão se reflete no cálculo dos potenciais produtivos, conforme exposto na Tabela 7.

Tabela 7

Cálculo de potenciais produtivos fixos e variáveis

\begin{tabular}{|c|c|c|c|c|c|c|c|c|c|c|c|}
\hline PO & $\begin{array}{l}\text { UEPs/h } \\
\text { Fixa }\end{array}$ & $\begin{array}{l}\text { UEPs/h } \\
\text { Variável }\end{array}$ & $\begin{array}{l}\text { UEPs/h } \\
\text { Total }\end{array}$ & PO & $\begin{array}{l}\text { UEPs/h } \\
\text { Fixa }\end{array}$ & $\begin{array}{l}\text { UEPs/h } \\
\text { Variável }\end{array}$ & $\begin{array}{l}\text { UEPs/h } \\
\text { Total }\end{array}$ & PO & $\begin{array}{l}\text { UEPs/h } \\
\text { Fixa }\end{array}$ & $\begin{array}{l}\text { UEPs/h } \\
\text { Variável }\end{array}$ & $\begin{array}{c}\text { UEPs/h } \\
\text { Total }\end{array}$ \\
\hline PO-002 & 5,07 & 2,59 & 7,66 & PO-038 & 10,03 & 3,72 & 13,75 & PO-064 & 10,02 & 3,59 & 13,62 \\
\hline PO-004 & 4,84 & 2,91 & 7,75 & PO-040 & 7,73 & 2,40 & 10,13 & PO-070 & 10,42 & 3,80 & 14,22 \\
\hline PO-006 & 4,22 & 3,00 & 7,22 & PO-044 & 5,08 & 1,64 & 6,72 & PO-072 & 24,21 & 7,46 & 31,67 \\
\hline PO-008 & 10,16 & 3,49 & 13,65 & PO-046 & 0,29 & 0,46 & 0,75 & PO-074 & 4,89 & 2,92 & 7,81 \\
\hline PO-010 & 4,78 & 1,97 & 6,75 & PO-048 & 6,21 & 1,90 & 8,11 & PO-076 & 5,29 & 2,05 & 7,34 \\
\hline PO-012 & 4,77 & 1,71 & 6,48 & PO-050 & 5,86 & 2,04 & 7,90 & PO-078 & 7,70 & 2,38 & 10,08 \\
\hline PO-014 & 5,81 & 2,52 & 8,33 & PO-052 & 3,72 & 2,56 & 6,28 & PO-080 & 3,66 & 1,96 & 5,62 \\
\hline PO-016 & 6,19 & 1,88 & 8,08 & PO-054 & 5,06 & 2,58 & 7,63 & PO-082 & 6,57 & 2,34 & 8,91 \\
\hline PO-030 & 7,96 & 3,47 & 11,43 & PO-056 & 5,04 & 3,70 & 8,74 & PO-084 & 5,24 & 3,04 & 8,28 \\
\hline PO-032 & 11,03 & 4,26 & 15,29 & PO-058 & 5,26 & 3,93 & 9,20 & PO-086 & 5,23 & 1,68 & 6,92 \\
\hline PO-034 & 5,09 & 1,65 & 6,74 & PO-060 & 10,40 & 3,18 & 13,58 & PO-090 & 6,23 & 1,99 & 8,22 \\
\hline PO-036 & 5,08 & 1,64 & 6,72 & PO-062 & 4,96 & 2,65 & 7,61 & & & & \\
\hline
\end{tabular}

$\mathrm{Na}$ etapa de operacionalização do método, por outro lado, esta lógica se desdobra nos resultados apresentados de forma resumida na Tabela 8. As Horas Disponíveis Teóricas representam o turno de trabalho e a quantidade de recursos disponíveis. As Horas Disponíveis Previstas são calculadas a partir das horas normalmente trabalhadas em cada posto, descontando-se as perdas consideradas normais. Por fim, as Horas Produzidas são aquelas justificadas pela fabricação dos itens no período. A Ociosidade é dada pela diferença entre a hora teórica e a 
prevista, enquanto que a Ineficiência é obtida pela diferença entre a hora prevista e a de fato produzida. Destaca-se a ocorrência de ineficiências negativas, as quais são indicativas de eventuais erros em roteiros de produção, ou mesmo, no procedimento de apontamento de horas.

A multiplicação das horas produzidas pelos potenciais (fixos e variáveis) gera o total de UEPs no período, neste caso, 32.251,2 UEPs fixas e 14.086,4 UEPs variáveis. Da mesma forma, o produto das horas ineficientes pelos potenciais resultou no esforço produtivo gasto com ineficiências do processo. Assim, o esforço total gerado pela produção no período analisado foi de 56.141,3 UEPs.

Dadas as horas disponíveis teóricas de cada posto e seus respectivos potenciais, calcula-se, na última coluna da tabela, a capacidade total de geração de esforços, que neste processo é de 64.161,5 UEPs por mês. A diferença entre a capacidade total e o esforço total realizado representa a ociosidade do sistema, a qual pode ser dividida nas parcelas fixa e variável, com a multiplicação das horas ociosas pelos potenciais produtivos. Importante reforçar o fato de que, ao não utilizar sua capacidade total, apenas a parcela fixa dos custos relacionados à ociosidade é de fato perdida, dado que a parcela variável não é utilizada, caso não haja produção. Sendo assim, a ociosidade fixa de 5.573,20 UEPs pode ser considerada uma produção potencial, que representa o quanto a mais de esforço o sistema poderia produzir, dado que a estrutura fixa não foi utilizada. Conclui-se, assim, que a capacidade potencial da empresa neste período foi de $61.714,5$ UEPs.

Nota-se que alguns postos são mais dependentes da estrutura fixa do que outros, gerando proporcionalmente mais UEPs fixas como, por exemplo, os postos 006, 070 e 072. Eles possuem uma proporção maior de custos de mão de obra, os quais são predominantemente fixos e são as operações mais penalizadas pela não utilização da capacidade total do sistema, gerando um potencial maior de UEPs não utilizadas. A tomada de ações visando a um melhor aproveitamento desses POs traria um ganho econômico mais relevante à empresa.

\section{Tabela 8}

Cálculo de produção e capacidade em UEPs fixas e variáveis 
Avaliação de Contribuições Teóricas ao Método das Unidades de Esforço de Produção (UEPs)

Thiago Leal Summchen Valentim

\begin{tabular}{|c|c|c|c|c|c|c|c|c|c|c|c|c|c|c|c|c|}
\hline POs & $\begin{array}{l}\text { UEPs/h } \\
\text { Fixa }\end{array}$ & $\begin{array}{c}\text { UEPs/h } \\
\text { Variável }\end{array}$ & $\begin{array}{c}\text { UEPs/h } \\
\text { Total }\end{array}$ & $\begin{array}{l}\text { Horas } \\
\text { Disp. } \\
\text { Teóricas }\end{array}$ & Ociosidade & $\begin{array}{l}\text { Horas } \\
\text { Disp. } \\
\text { Previstas }\end{array}$ & Inefic. & $\begin{array}{c}\text { Horas } \\
\text { Produzidas }\end{array}$ & $\begin{array}{l}\text { UEPs } \\
\text { Fixas }\end{array}$ & $\begin{array}{c}\text { UEPs } \\
\text { Variáveis }\end{array}$ & $\begin{array}{c}\text { UEPs } \\
\text { Ineficientes }\end{array}$ & $\begin{array}{l}\text { Esforço } \\
\text { Total }\end{array}$ & $\begin{array}{c}\text { Ociosidade } \\
\text { Fixa }\end{array}$ & $\begin{array}{c}\text { Capacidade } \\
\text { Potencial }\end{array}$ & $\begin{array}{l}\text { Ociosidade } \\
\text { Variável }\end{array}$ & $\begin{array}{c}\text { Capacidade } \\
\text { Total }\end{array}$ \\
\hline PO-002 & 5,11 & 2,91 & 8,01 & 75,60 & 9,45 & 66,15 & 31,13 & 35,02 & 178,82 & 101,82 & 249,46 & 530,10 & 48,25 & 578,35 & 27,47 & 605,83 \\
\hline $\mathrm{PO}-004$ & 4,84 & 2,67 & 7,51 & 113,40 & 14,18 & 99,23 & $-31,63$ & 130,85 & 633,51 & 349,00 & $-237,49$ & 745,02 & 68,63 & 813,65 & 37,81 & 851,45 \\
\hline PO-006 & 11,50 & 4,63 & 16,13 & 264,60 & 33,08 & 231,53 & $-6,23$ & 237,75 & $2.733,82$ & $1.100,47$ & $-100,40$ & $3.733,88$ & 380,32 & $4.114,20$ & 153,09 & $4.267,29$ \\
\hline PO-008 & 9,97 & 2,89 & 12,86 & 18,90 & 2,36 & 16,54 & 14,04 & 2,50 & 24,92 & 7,23 & 180,52 & 212,67 & 23,55 & 236,22 & 6,83 & 243,05 \\
\hline PO-010 & 4,80 & 2,15 & 6,95 & 56,70 & 7,09 & 49,61 & $-5,50$ & 55,11 & 264,75 & 118,32 & $-38,20$ & 344,87 & 34,05 & 378,92 & 15,22 & 394,14 \\
\hline PO-012 & 4,78 & 1,81 & 6,59 & 18,90 & 2,36 & 16,54 & 11,84 & 4,70 & 22,49 & 8,49 & 78,01 & 108,99 & 11,30 & 120,29 & 4,27 & 124,55 \\
\hline PO-014 & 11,20 & 3,97 & 15,17 & 151,20 & 18,90 & 132,30 & 21,65 & 110,65 & $1.239,01$ & 438,99 & 328,38 & $2.006,38$ & 211,64 & $2.218,02$ & 74,99 & $2.293,01$ \\
\hline PO-016 & 6,21 & 1,89 & 8,10 & 56,70 & 7,09 & 49,61 & 33,81 & 15,80 & 98,19 & 29,83 & 273,86 & 401,88 & 44,03 & 445,91 & 13,38 & 459,29 \\
\hline $\mathrm{PO}-030$ & 7,99 & 3,48 & 11,47 & 189,00 & 23,63 & 165,38 & 102,62 & 62,76 & 501,31 & 218,35 & $1.176,74$ & $1.896,40$ & 188,72 & $2.085,12$ & 82,20 & $2.167,32$ \\
\hline PO-032 & 11,06 & 4,27 & 15,34 & 189,00 & 23,63 & 165,38 & 45,31 & 120,07 & $1.328,26$ & 513,14 & 694,88 & $2.536,28$ & 261,36 & $2.797,64$ & 100,97 & $2.898,61$ \\
\hline $\mathrm{PO}-034$ & 5,10 & 1,66 & 6,76 & 189,00 & 23,63 & 165,38 & 125,92 & 39,46 & 201,41 & 65,43 & 851,51 & $1.118,35$ & 120,59 & $1.238,94$ & 39,18 & $1.278,11$ \\
\hline PO-036 & 5,10 & 1,65 & 6,74 & 189,00 & 23,63 & 165,38 & $-3,85$ & 169,23 & 862,28 & 279,14 & $-25,98$ & $1.115,45$ & 120,38 & $1.235,82$ & 38,97 & $1.274,79$ \\
\hline PO-038 & 10,00 & 3,92 & 13,92 & 94,50 & 11,81 & 82,69 & 21,31 & 61,38 & 613,66 & 240,75 & 296,69 & $1.151,10$ & 118,11 & $1.269,21$ & 46,34 & $1.315,55$ \\
\hline PO-040 & 7,75 & 2,41 & 10,16 & 0,00 & 0,00 & 0,00 & 0,00 & 0,00 & 0,00 & 0,00 & 0,00 & 0,00 & 0,00 & 0,00 & 0,00 & 0,00 \\
\hline PO-044 & 5,10 & 1,65 & 6,74 & 189,00 & 23,63 & 165,38 & 46,18 & 119,19 & 607,35 & 196,61 & 311,49 & $1.115,45$ & 120,38 & $1.235,82$ & 38,97 & $1.274,79$ \\
\hline $\mathrm{PO}-046$ & 0,29 & 0,46 & 0,75 & 189,00 & 23,63 & 165,38 & $-14,16$ & 179,53 & 51,49 & 83,25 & $-10,63$ & 124,12 & 6,78 & 130,89 & 10,96 & 141,85 \\
\hline PO-048 & 6,23 & 1,91 & 8,14 & 56,70 & 7,09 & 49,61 & 43,78 & 5,83 & 36,35 & 11,12 & 356,30 & 403,78 & 44,17 & 447,95 & 13,51 & 461,46 \\
\hline PO-050 & 5,88 & 2,04 & 7,93 & 378,00 & 47,25 & 330,75 & 197,25 & 133,50 & 785,19 & 272,86 & $1.563,29$ & $2.621,33$ & 277,90 & $2.899,23$ & 96,57 & $2.995,81$ \\
\hline PO-052 & 3,73 & 2,56 & 6,30 & 189,00 & 23,63 & 165,38 & 28,84 & 136,54 & 509,36 & 350,20 & 181,53 & $1.041,09$ & 88,13 & $1.129,23$ & 60,59 & $1.189,82$ \\
\hline PO-054 & 5,09 & 2,89 & 7,99 & 75,60 & 9,45 & 66,15 & 14,88 & 51,27 & 261,07 & 148,34 & 118,86 & 528,27 & 48,12 & 576,40 & 27,34 & 603,74 \\
\hline PO-056 & 5,01 & 3,10 & 8,11 & 94,50 & 11,81 & 82,69 & 22,87 & 59,82 & 299,65 & 185,32 & 185,44 & 670,41 & 59,18 & 729,59 & 36,60 & 766,18 \\
\hline PO-058 & 5,28 & 3,94 & 9,22 & 132,30 & 16,54 & 115,76 & 11,38 & 104,38 & 551,19 & 411,68 & 104,96 & $1.067,83$ & 87,32 & $1.155,15$ & 65,22 & $1.220,37$ \\
\hline PO-060 & 10,43 & 3,19 & 13,62 & 37,80 & 4,73 & 33,08 & $-1,93$ & 35,00 & 365,09 & 111,75 & $-26,23$ & 450,61 & 49,29 & 499,90 & 15,09 & 514,99 \\
\hline PO-062 & 4,98 & 2,66 & 7,63 & 189,00 & 23,63 & 165,38 & 147,39 & 17,99 & 89,51 & 47,80 & $1.125,19$ & $1.262,50$ & 117,57 & $1.380,07$ & 62,78 & $1.442,85$ \\
\hline PO-064 & 9,99 & 3,67 & 13,66 & 75,60 & 9,45 & 66,15 & 23,10 & 43,05 & 430,06 & 157,78 & 315,49 & 903,33 & 94,41 & 997,75 & 34,64 & $1.032,38$ \\
\hline PO-070 & 10,45 & 3,81 & 14,27 & 151,20 & 18,90 & 132,30 & $-8,00$ & 140,30 & $1.466,56$ & 535,05 & $-114,13$ & $1.887,48$ & 197,56 & $2.085,04$ & 72,08 & $2.157,12$ \\
\hline PO-072 & 24,28 & 7,48 & 31,76 & 189,00 & 23,63 & 165,38 & $-60,78$ & 226,15 & $5.490,72$ & $1.692,31$ & $-1.930,41$ & $5.252,62$ & 573,59 & $5.826,21$ & 176,79 & $6.003,00$ \\
\hline PO-074 & 4,90 & 2,93 & 7,83 & 756,00 & 94,50 & 661,50 & 60,02 & 601,48 & $2.947,73$ & $1.764,33$ & 470,22 & $5.182,28$ & 463,13 & $5.645,40$ & 277,20 & $5.922,60$ \\
\hline PO-076 & 5,31 & 2,05 & 7,36 & 567,00 & 70,88 & 496,13 & 207,23 & 288,89 & $1.533,24$ & 593,37 & $1.525,47$ & $3.652,08$ & 376,15 & $4.028,23$ & 145,57 & $4.173,80$ \\
\hline PO-078 & 7,72 & 2,38 & 10,11 & 0,00 & 0,00 & 0,00 & 0,00 & 0,00 & 0,00 & 0,00 & 0,00 & 0,00 & 0,00 & 0,00 & 0,00 & 0,00 \\
\hline PO-080 & 6,90 & 2,88 & 9,77 & 151,20 & 18,90 & 132,30 & $-8,71$ & 141,01 & 972,58 & 405,42 & $-85,11$ & $1.292,89$ & 130,36 & $1.423,25$ & 54,34 & $1.477,59$ \\
\hline PO-082 & 6,59 & 2,35 & 8,94 & 189,00 & 23,63 & 165,38 & $-16,71$ & 182,08 & $1.200,50$ & 427,06 & $-149,35$ & $1.478,21$ & 155,76 & $1.633,97$ & 55,41 & $1.689,38$ \\
\hline PO-084 & 5,26 & 3,05 & 8,30 & $1.323,00$ & 165,38 & $1.157,63$ & 193,33 & 964,29 & $5.069,71$ & $2.937,96$ & $1.605,47$ & $9.613,14$ & 869,45 & $10.482,59$ & 503,86 & $10.986,45$ \\
\hline PO-086 & 5,25 & 1,69 & 6,94 & 189,00 & 23,63 & 165,38 & 31,74 & 133,63 & 701,27 & 225,63 & 220,16 & $1.147,06$ & 123,98 & $1.271,04$ & 39,89 & $1.310,93$ \\
\hline PO-090 & 6,25 & 2,00 & 8,25 & 75,60 & 9,45 & 66,15 & 37,32 & 28,83 & 180,15 & 57,60 & 307,69 & 545,43 & 59,04 & 604,48 & 18,88 & 623,35 \\
\hline TOTAL & & & & & & & & & $32.251,2$ & $14.086,4$ & $9.803,7$ & $56.141,3$ & $5.573,20$ & $61.714,5$ & $2.446,99$ & $64.161,5$ \\
\hline
\end{tabular}


Seguindo esta lógica, o método permite atribuir valor econômico às UEPs produzidas e às perdas do sistema. Dada a capacidade potencial de 57.667 UEPs, procede-se à monetarização da UEP pelo princípio de Absorção Ideal, conforme apresentado na Tabela 9.

Tabela 9

Monetarização das UEPs por Absorção Ideal

\begin{tabular}{|c|c|c|}
\hline Total em UEPs & $\begin{array}{c}\text { Custos de } \\
\text { Transformação }\end{array}$ & Custo por UEP \\
\hline $64.161,50$ & $\mathrm{R} \$ 288.668,00$ & $\mathrm{R} \$ 4,50$ \\
\hline
\end{tabular}

Por fim, a Tabela 10 apresenta a valorização econômica das perdas do processo. Os resultados foram obtidos pela multiplicação dos valores em UEPs apresentados na Tabela 8 pelo seu custo unitário apresentado na Tabela 9.

Tabela 10

Valorização econômica das perdas do sistema

\begin{tabular}{|c|c|c|c|c|c|c|c|c|c|c|c|}
\hline & UEPs & $s$ boas fixas & & $\begin{array}{l}\text { UEPs boas } \\
\text { variáveis }\end{array}$ & Ineficiêcia & $\begin{array}{c}\text { Esforço } \\
\text { Produtivo }\end{array}$ & Oc & $\begin{array}{l}\text { iosidade } \\
\text { Fixa }\end{array}$ & $\begin{array}{c}\text { Esforço } \\
\text { Potencial }\end{array}$ & $\begin{array}{l}\text { Ociosidade } \\
\text { Variável }\end{array}$ & Esforço Total \\
\hline UEPs & & $32.251,2$ & & $14.086,4$ & $9.803,7$ & $56.141,3$ & & $5.573,2$ & $61.714,5$ & $2.447,0$ & $64.161,5$ \\
\hline Custo $(R \$)$ & $\mathrm{R} \$$ & $145.100,87$ & $\mathrm{R} \$$ & $63.375,90$ & $\mathrm{R} \$ 44.107,67$ & $\mathrm{R} \$ 252.584,44$ & $\mathrm{R} \$$ & $25.074,30$ & $\mathrm{R} \$ 277.658,74$ & $\mathrm{R} \$ 11.009,21$ & $\mathrm{R} \$ 288.668,00$ \\
\hline$\%$ Custo & & $50 \%$ & & $22 \%$ & $15 \%$ & $87 \%$ & & $9 \%$ & $96 \%$ & $4 \%$ & $100 \%$ \\
\hline
\end{tabular}

Conclui-se que, de toda a capacidade mensal do processo, um pouco mais de dois terços $(72 \%)$ foi utilizada na produção de UEPs chamadas boas, as quais são esforços empregados na fabricação propriamente dita dos produtos, o que representa um custo de $R \$ 208.476,77$. Outros $15 \%$ da capacidade foram utilizados gerando esforços para cobrir ineficiências de produção. A ociosidade representa $13 \%$ da capacidade total, da qual a parcela fixa é mais representativa. Ao não trabalhar com sua capacidade total, a empresa deixou de utilizar esforços em potencial, e gastou $9 \%$ de seus custos de transformação totais para pagar uma estrutura fixa capaz de produzir mais 5.573,20 UEPs. Logo, da totalidade de custos de transformação, 96,1\% foram 
gastos com a geração de UEPs potencialmente utilizáveis, enquanto que apenas $(3,9 \%)$ representam gastos perdidos pela subutilização da estrutura produtiva.

A contribuição do método para o custeio de perdas pode ser destacada na comparação entre os percentuais apresentados na Tabela 10 com os obtidos, analisando-se unicamente as horas de produção, conforme exposto na Tabela 11.

Tabela 11

Análise das horas produzidas.

\begin{tabular}{|ccccc|}
\hline & Horas & \% & UEPs & $\%$ \\
\hline Produção & 4638,0 & $68,20 \%$ & $46.337,6$ & $72,20 \%$ \\
Ineficiência & 1315,5 & $19,30 \%$ & $9.803,7$ & $15,30 \%$ \\
Ociosidade & 850,5 & $12,50 \%$ & $8.020,2$ & $12,50 \%$ \\
Capacidade & 6804,0 & & $64.161,5$ & \\
\hline
\end{tabular}

Analisando-se exclusivamente as horas produzidas, é possível concluir que $68,2 \%$ da capacidade total da empresa foram empregados em produção efetiva, enquanto 19,3\% foram perdidos por ineficiências de processo. Percebe-se a diferença em relação aos percentuais da Tabela 10, pois o método das UEPs considera o valor econômico das horas produtivas, e a sua aplicação permite uma avaliação da utilização diferenciada da capacidade. Conclui-se que o mix produtivo da empresa utilizou proporcionalmente mais de recursos com maior potencial produtivo. Adicionalmente, permite avaliar, de forma estratificada, as causas da ociosidade e seu impacto econômico na produção da empresa.

\subsubsection{UEPs Parciais}

Uma segunda contribuição deste trabalho com relação à aplicação do método das UEPs diz respeito ao conceito de UEPs parciais. Tradicionalmente, na etapa de operacionalização do método, ocorre a monetarização da UEP, obtendo-se um índice de custo de transformação por unidade de esforço, usualmente pelo princípio da 
Absorção Total. Este custo por unidade é, então, utilizado para multiplicar os equivalentes dos produtos, resultando no seu custo unitário.

Em empresas multiprodutoras, é comum a existência de linhas de produtos que utilizem a estrutura produtiva de formas distintas. Ocasionalmente, algumas linhas irão utilizar-se mais de certos grupos de operações, enquanto outras linhas podem utilizarse da estrutura de forma mais homogênea. Assim, a utilização de um único índice de custo por UEP gera uma distorção, distribuindo a ineficiência do processo de forma equivalente a todos os produtos, embora nem todos a absorvam na mesma proporção.

Diante desta problemática, propõe-se o cálculo de UEPs parciais, com a criação de grupos de postos operativos. Esses grupos podem ser definidos por conveniência, de acordo com o mix produtivo da empresa, desde que seja possível a obtenção do custo total de transformação estratificado para cada um dos grupos. A título de ilustração, no estudo de caso apresentado, optou-se por reagrupar os POs nos centros de custos que os originaram. Os $\mathrm{R} \$ 288.668$, apresentados anteriormente, são o resultado da soma dos custos de transformação de cada centro. Dado que, neste caso, os grupos de POs coincidem com a estrutura de centros de custos, foi possível determinar os custos de transformação de cada grupo, bem como a produção total de cada um, pela soma das UEPs produzidas em cada PO. A Tabela 12 ilustra este cálculo. 
Tabela 12

\section{Cálculo de UEPs parciais}

\begin{tabular}{|c|c|c|c|c|c|c|c|c|c|c|c|c|c|}
\hline Grupo & POs & UEPs & & Custo & & UEP & Grupo & POs & UEPs & & Custo & & UEP \\
\hline \multirow{6}{*}{ CC 1} & PO-034 & $1.114,97$ & \multirow{6}{*}{$\mathrm{R} \$$} & \multirow{6}{*}{$46.268,93$} & \multirow{6}{*}{$\mathrm{R} \$$} & \multirow{6}{*}{3,26} & \multirow{4}{*}{$\operatorname{cc} 6$} & PO-002 & 506,85 & \multirow{4}{*}{$\mathrm{R} \$$} & \multirow{4}{*}{$21.318,56$} & \multirow{4}{*}{$\mathrm{R} \$$} & \multirow{4}{*}{7,62} \\
\hline & PO-036 & $1.112,08$ & & & & & & PO-054 & 505,03 & & & & \\
\hline & PO-044 & $1.112,08$ & & & & & & PO-056 & 722,52 & & & & \\
\hline & PO-046 & 123,74 & & & & & & PO-058 & $1.064,55$ & & & & \\
\hline & PO-084 & $9.584,14$ & & & & & \multirow{7}{*}{ CC 7} & PO-030 & $1.890,68$ & & & & \\
\hline & $\mathrm{PO}-086$ & $1.143,60$ & & & & & & PO-032 & $2.528,63$ & & & & \\
\hline \multirow{3}{*}{ CC 2} & PO-008 & 225,77 & & & & & & PO-052 & $1.037,95$ & & & & \\
\hline & PO-038 & $1.137,01$ & $\mathrm{R} \$$ & $18.667,16$ & $\mathrm{R} \$$ & 8,25 & & PO-060 & 449,25 & $\mathrm{R} \$$ & $67.077,00$ & $\mathrm{R} \$$ & 4,70 \\
\hline & $\mathrm{PO}-064$ & 900,88 & & & & & & PO-062 & $1.258,69$ & & & & \\
\hline \multirow{4}{*}{ CC 3} & PO-006 & $1.672,57$ & & & & & & PO-070 & $1.881,79$ & & & & \\
\hline & PO-014 & $1.102,59$ & $\mathrm{R} \$$ & $29.066,19$ & $\mathrm{R} \$$ & 8,26 & & PO-072 & $5.236,78$ & & & & \\
\hline & $\mathrm{PO}-080$ & 743,52 & & & & & \multirow{2}{*}{ CC 8} & PO-040 & - & \multirow{2}{*}{$\mathrm{R} \$$} & \multirow{2}{*}{$6.365,73$} & \multirow{2}{*}{$\mathrm{R} \$$} & \multirow{2}{*}{ - } \\
\hline & PO-004 & 769,48 & & & & & & PO-078 & - & & & & \\
\hline \multirow[t]{2}{*}{$\mathrm{CC} 4$} & PO-010 & 334,96 & $\mathrm{R} \$$ & $15.413,26$ & $\mathrm{R} \$$ & 12,72 & \multirow{3}{*}{ CC 9} & PO-016 & 400,66 & & & & \\
\hline & PO-012 & 107,16 & & & & & & PO-048 & 402,56 & $\mathrm{R} \$$ & $10.865,55$ & $\mathrm{R} \$$ & 8,07 \\
\hline \multirow{4}{*}{ CC 5} & PO-050 & $2.614,13$ & \multirow{4}{*}{$\mathrm{R} \$$} & \multirow{4}{*}{$21.295,48$} & \multirow{4}{*}{$\mathrm{R} \$$} & \multirow{4}{*}{3,40} & & PO-090 & 543,79 & & & & \\
\hline & PO-076 & $3.641,14$ & & & & & $\mathrm{CC} 10$ & $\mathrm{PO}-074$ & $5.166,64$ & $\mathrm{R} \$$ & $32.132,89$ & $\mathrm{R} \$$ & 6,22 \\
\hline & & & & & & & CC 11 & PO-082 & $1.473,75$ & $\mathrm{R} \$$ & $20.197,24$ & $\mathrm{R} \$$ & 13,70 \\
\hline & & & & & & & & TAL & $52.509,94$ & $\mathrm{R} \$$ & $288.668,00$ & & 5,50 \\
\hline
\end{tabular}

A tabela mostra que este procedimento permite a monetarização da UEP de forma parcial, definindo um valor por agrupamento de POs. É possível perceber diferenças significativas, em que os grupos 11 e 4 possuem uma UEP parcial mais cara que os demais, o que está de acordo com a proporção entre os custos-hora utilizados pelo método atual, apresentados na Tabela 1.

Comparativamente ao custo médio da UEP de $\$ 6,75$, nota-se que o esforço produzido nos grupos destacados é consideravelmente maior, e os produtos que consomem mais dessas operações devem ser mais onerados pelo sistema. Todavia, a média ponderada tende ao valor mais baixo por conta de grupos como 1 e 7 , os quais possuem uma UEP mais barata e uma maior parcela da produção total. Para ilustrar a contribuição da utilização de UEPs parciais, foram selecionadas duas linhas de produtos da empresa que utilizam a estrutura produtiva de formas distintas. A Tabela 13 mostra o cálculo dos custos unitários de transformação de ambas as linhas, utilizando o conceito de UEPs parciais. 
Tabela 13

Cálculo de custos de transformação por UEPs parciais

\begin{tabular}{|c|c|c|c|c|c|c|c|c|c|c|c|c|c|}
\hline & & CC 1 & CC 2 & CC 3 & CC 4 & CC 5 & CC 6 & CC 7 & CC 8 & CC 9 & CC 10 & CC 11 & TOTAL \\
\hline \multirow{2}{*}{ Linha B } & UEPs & - & - & - & - & - & - & 0,034 & - & - & - & - & 0,034 \\
\hline & Custo (R\$) & $\mathrm{R} \$$ - & $\mathrm{R} \$$ - & $\mathrm{R} \$$ - & $\mathrm{R} \$$ - & $\mathrm{R} \$$ - & $\mathrm{R} \$$ - & $\mathrm{R} \$ 0,16$ & $\mathrm{R} \$$ - & $\mathrm{R} \$$ - & $\mathrm{R} \$$ - & $\mathrm{R} \$$ - & $\mathrm{R} \$ 0,03$ \\
\hline \multirow{2}{*}{$\begin{array}{c}\text { Linha } \\
\text { Químicos }\end{array}$} & UEPs & 0,177 & 0,208 & - & 0,138 & 0,264 & 0,141 & - & - & - & 0,048 & - & 0,975 \\
\hline & Custo (R\$) & $\mathrm{R} \$ 0,58$ & $\mathrm{R} \$ 1,71$ & $\mathrm{R} \$$ - & $\mathrm{R} \$ 1,75$ & $\mathrm{R} \$ 0,90$ & R\$ 1,07 & $\mathrm{R} \$$ - & $\mathrm{R} \$$ - & $\mathrm{R} \$$ - & $\mathrm{R} \$$ - & $\mathrm{R} \$$ - & $\mathrm{R} \$ 6,01$ \\
\hline
\end{tabular}

Fica claro, pela análise da tabela, que a produção destas duas linhas concentrase em grupos diferentes de POs. Enquanto os produtos da Linha B necessitam apenas de operações do grupo 7, os itens da Linha Químicos têm um processo de fabricação mais diversificado. Ao multiplicar os equivalentes de cada linha pelas UEPs parciais, obtêm-se os custos de transformação de $R \$ 0,03$ e $R \$ 6,01$, respectivamente. Caso o cálculo fosse realizado com o custo médio da UEP, os produtos da Linha B custariam $\mathrm{R} \$ 0,21$, e os da Linha Químicos, $R \$ 6,18$. Essa diferença explica-se pelo fato de a Linha B utilizar um conjunto de operações mais eficiente, enquanto que os itens da Linha Químicos estão absorvendo esforços ineficientes de vários pontos do processo produtivo.

O cálculo da UEP parcial permite a avaliação econômica da utilização diferenciada da estrutura produtiva, servindo de apoio para a discussão sobre o impacto da utilização da capacidade de produção. A partir dos números apresentados, percebese que a UEP parcial incorpora a distribuição diferenciada da ociosidade e das ineficiências do sistema, mitigando o problema do grau de média da UEP total, além de indicar quais pontos do processo são mais impactados por esta utilização heterogênea de capacidade. A Tabela 12 evidencia essa questão, mostrando que os grupos de POs 2, 4 e 9 sofrem mais com ociosidade e ineficiências; logo, possuem um custo de UEP mais elevado e devem, assim, onerar os produtos que mais os consomem. Por outro lado, produtos como os da Linha $B$, que consomem recursos mais eficientes, não devem pagar pela ineficiência dos outros pontos do processo, conforme apresentado na Tabela 13. 
No limite, esta lógica de parcialização do cálculo da UEP poderia ser levada ao nível do posto operativo, com a obtenção de um custo por UEP para cada PO. Esta estratificação depende do nível de informação de custos que a empresa possui e pode não agregar valor de um ponto de vista de custo/benefício. Importante ressaltar também que o cálculo da UEP parcial não depõe contra a UEP total, apenas apresenta uma visão complementar, a qual busca minimizar os efeitos do grau de média. A obtenção de um índice global permanece importante, sob um ponto de vista de avalição do desempenho geral do processo ao longo do tempo, comparação entre processos distintos, ou mesmo, custeio de produtos em um processo cuja capacidade é utilizada de forma mais homogênea.

\section{CONSIDERAÇÕES FINAIS}

O método de custeio das UEPs surgiu como uma forma de alocar, com maior precisão, os custos de transformação de empresas industriais multiprodutoras, tornando-se, ao longo dos anos, uma alternativa aos métodos ditos tradicionais, os quais tendem a apresentar distorções maiores na distribuição de custos indiretos de fabricação aos produtos. Neste contexto, o presente artigo teve como objetivo principal a avaliação de duas contribuições conceituais ao método: a divisão de UEPs em fixas e variáveis e o cálculo de UEPs parciais. A primeira visa ampliar o escopo do método no que diz respeito à análise econômica de perdas e capacidade produtiva e concentra-se na fase de Implantação do método, enquanto a segunda busca minimizar distorções no custeio de produtos e foca na fase de Operacionalização. Para tanto, fundamenta-se no estudo de caso de Bastos (2015), o qual é utilizado para validar as contribuições propostas.

A análise da aplicação do método permitiu observar que ele, de fato, é adequado à realidade da empresa, a qual se caracteriza por um processo produtivo heterogêneo $\mathrm{e}$ um mix extenso de produtos. A lógica de implantação do método levou à identificação de 35 postos operativos, que anteriormente eram tratados como 11 centros de custos. 
A parametrização econômica destes postos permitiu confirmar a heterogeneidade do processo, assim como desenvolver um conhecimento mais aprofundado acerca da estrutura de custos da empresa. A comparação entre os custos unitários de transformação obtidos com o método das UEPs e o atual método de custeio destaca a capacidade do primeiro de tornar mais precisa a distribuição de custos indiretos.

O artigo buscou realizar duas contribuições teóricas ao método das UEPs. Inicialmente, discutiu-se a criação de UEPs fixas e variáveis e seus impactos na implantação e operacionalização do método. Apresentou-se a lógica de cálculo proposta, bem como os resultados obtidos com essa divisão. Argumenta-se que esta abordagem contribui com a identificação da real capacidade produtiva da empresa nos seus aspectos econômicos, pois faz uma distinção entre a estrutura de produção fixa e variável, considerando que apenas a primeira é afetada pela não utilização da capacidade total. Por consequência, a distinção entre esforços produtivos fixos e variáveis permite uma análise mais precisa das perdas econômicas do processo. Por fim, o artigo propõe o conceito de UEPs parciais e discute seu impacto no cálculo dos custos de transformação, concluindo que a valorização das UEPs por grupos de POs permite minimizar distorções na distribuição de custos ineficientes às diferentes linhas de produtos da empresa.

Assim, o trabalho buscou não somente validar o método das UEPs como uma opção moderna de custeio de produtos, como também contribuir com o seu desenvolvimento conceitual. Destaca-se que, aqui, o método foi tratado exclusivamente sob um ponto de vista do custeio de produtos, não tendo sido abordada a questão das medidas de desempenho operacionais que ele proporciona a partir da unificação da produção.

\section{REFERÊNCIAS}

Allora, V., \& Gantzel, G. L. (1996). UP' - Unidade de Produção (UEP' - Unidade de Esforço de Produção), conceitos básicos e aplicação prática. Anais do Congresso Brasileiro de Custos, Curitiba, Paraná, Brasil, 3. 
Bastos, R. (2015). Aplicação da Metodologia da UEP como ferramenta para geração de Indicadores de Desempenho em uma Indústria da área de instrumentos de medição. (Dissertação de Mestrado Profissional). Universidade Federal do Rio Grande do Sul - UFRGS, Porto Alegre, Rio Grande do Sul, Brasil.

Bornia, A. C. (2010). Análise gerencial de custos em empresas modernas. Porto Alegre, Bookman.

Cambruzzi, D., Balen, F. V., \& Morozini, J. F. (2009). Unidade de esforço de produção (UEP) como método de custeio: implantação de modelo em uma indústria de laticínios. ABCustos, 4(1), 101-123.

Campagnolo, R. R., Souza, J. S., \& Kliemann Neto, F. J. (2009). Seria mesmo o TimeDriven $A B C$ (TDABC) um método de custeio inovativo? Uma análise comparativa entre o TDABC e o método da unidade de esforço de produção (UEP). Anais do Congresso Internacional de Costos y Gestión, Patagonia, Argentina, 11.

Fadanelli, V. G. (2007). A utilização do método da unidade de esforço de produção como modelo de gestão de custos - o caso de empresa do ramo metalúrgico. (Dissertação de Mestrado Profissional). Universidade Federal do Rio Grande do Sul - UFRGS, Porto Alegre, Rio Grande do Sul, Brasil.

Fagundes, A. B., Vaz, C. R., \& Hatakeyama, K. (2009). A relação entre os custos e receitas ambientais como principal indicador do desempenho econômico-ambiental das organizações. Revista Produção Online, 9(3), 442-465. Disponível em http://www.producaoonline.org.br/index.php/rpo/article/view/177/491. Acesso em: fev. 2017.

Fernandes, J. S. (2003). Sistematização de uma abordagem da medição de uma produção diversificada e seus desempenhos num ambiente industrial pelo método das unidades de esforço de produção - UEPs. (Dissertação de Mestrado). Universidade Federal do Rio Grande do Sul - UFRGS, Porto Alegre, Rio Grande do Sul, Brasil.

GIL, A. C. (2002). Métodos e técnicas de pesquisa social. São Paulo, Atlas.

Morozini, J. F., Gass, C. T., Caerpenedo, C. L. \& Zuffo, C. R. R. (2006). Aplicação da abordagem UEP em uma empresa do setor fabril: um estudo de caso. Sistemas \& Gestão, 01(2), 142-155.

Schwanke, A. L., \& Kliemann Neto, F. J. (2010). Aplicação do método matricial para melhoria da alocação dos custos indiretos - o caso de uma indústria 
metalmecânica. Anais do Congresso Internacional de Custos, Belo Horizonte, Brasil.

Valentim, T. L. S., Kliemann Neto, F. J., Correa, R.G.F., Denicol, J., \& Cassel, R. A. (2014). Proposta de sistemática de aplicação do método das UEPs: estudo de caso em empresa de produção sob encomenda. Anais do Congresso Brasileiro de Custos, Natal, Recife, Brasil, 21.

Wernke, R. \& Lembeck, M. (2008). Aplicação do método UEP em uma indústria de descartáveis. Revista do Conselho Regional de Contabilidade do Rio Grande do Sul, 132, 18-33.

Wernke, R., Junges, I. \& Cláudio, D. A. (2012). Indicadores não financeiros do método UEP aplicáveis à gestão de pequena indústria. Iberoamerican Journal of Industrial Engineering, 04(8), 125-145.

Data de Submissão: 20/02/2017

Data de Aceite: 04/06/2018 